\title{
A VITALIZAÇÃO DA LÍNGUA KOKAMA ALÉM DAS FRONTEIRAS ENTRE O BRASIL E PERU
}

\author{
Altaci Corrêa RUBIM (DD \\ Departamento de Linguística, Português e Línguas Clássicas \\ Instituto de Letras - Universidade de Brasília (UnB)
}

RESUMO

Vitalizar uma língua é dar força ou vigor à sua dinâmica de existência. É ter a língua nos rituais dos pajés, nas brincadeiras de roda, nas contações de histórias antigas, nas danças, nas músicas, nos artesanatos, nas vestimentas, nas pinturas e na vida da aldeia, mesmo que seja como segunda língua. Esse processo tem sido vivenciado pelo povo Kokama do Brasil e do Peru, por meio de decisões que levam a língua de seus ancestrais a ocupar espaços comunicativos dentro e fora das aldeias. Este artigo tem como objetivo apresentar a trajetória da vitalização da língua Kokama apresentada no evento "Viva Língua Viva", no ano internacional das lín-

EDITADO POR

- Marcus Maia (UFRJ)

- Bruna Franchetto (UFRJ)

REVISADO POR

- Ana Carolina (UFAM)

- Cilene Campetela (UNIFAP)

DATAS

- Recebido: 04/07/2020

- Aceito: 11/09/2020

- Publicado: 29/09/2020 guas indígenas de 2019. A vitalização está ligada à conquista do território por meio da língua, assim como a ocupação dos espaços físicos e digitais no século XXI, como os Centros de Ciências e Saberes Tradicionais Kokama, conhecidos como Museu Vivo, Lua Verde e Antonio Samias, e os Centros de Educação Escolar Indígena Atawanã Kuarachi Kokama e Tsetsu Kamutun, que são locais que vitalizam a língua. Nessa perspectiva, também são criados aplicativos que ocupam os espaços digitais produzidos por jovens, adultos e anciãos Kokama. A metodologia de pesquisa é baseada no mapeamento situacional de cunho etnográfico. Como resultado, observou-se que esses pequenos espaços vitalizam a língua, onde crianças, jovens e adultos encontram a função social da língua ao expressar sua cultura por meio dos atos de fala. 


\section{ABSTRACT}

To vitalize a language is to give strength or vigor to the dynamics of its existence. It means having the language in the rituals of the shamans, in playground, in the telling of traditional stories, in the dances, in the songs, in the crafts, in the traditional clothing, in the paintings, in the everyday life of the community, even if it is used as a second language. This process has been experienced by the Kokama people of Brazil and Peru, through decisions that lead the language of their ancestors to occupy communicative spaces inside and outside the villages. In this paper, I describe the work for the vitalization of the Kokama language, which was presented in the "Viva Língua Viva" conference as part of the celebrations of the International Year of Indigenous Languages in 2019. I show how vitalization is linked to the conquest of our traditional land through language, as well as the occupation of physical and digital spaces in the $21^{\text {st }}$ century. I describe several initiatives, like the Kokama Traditional Knowledge and Science and Knowledge Centers (known as Museu Vivo), the Lua Verde and Antonio Samias Centers, and the Atawanã Kuarachi Kokama and Tsetsu Kamutun Indigenous Education Centers, which are places that contribute to vitalize the language. I also discuss the development of digital applications created in collaborations with Kokama people from different generations, and have the goal of bringing the language to new domains. In this way, these initiatives can aid in the vitalization of the language, where children, young people and adults find the social function of language when expressing their culture through their speech.

\section{PALAVRAS-CHAVE}

Vitalização; Materiais didáticos físicos e digitais; Multiletramentos.

\section{KEYWORDS}

Vitalization; Physical and Digital Teaching Material; Multiliteracy. 


\section{INTRODUÇÃO}

Falar de línguas indígenas é falar de memórias, de histórias, de saberes, de espíritos ancestrais e de uma biblioteca com uma riqueza cultural e linguística imensurável. Quando os colonizadores chegaram ao Brasil, no século XVI, encontraram mais de 1300 línguas de diferentes troncos linguísticos. Nos registros dos viajantes, as línguas e culturas são retratadas como exóticas "alguns vocábulos há nelas de que não usam senão as fêmeas, e outros que não servem senão para machos" (GÂNDAVO, 2008, p. 134). Esse registro apresenta a marca de gênero presente em algumas línguas indígenas. O desconhecimento e o etnocentrismo criaram os estigmas e os preconceitos linguísticos que até os dias atuais são vivenciados pelos povos indígenas.

A política de Marquês de Pombal veio coroar a hegemonia da língua portuguesa em detrimento das demais línguas existentes na colônia de Portugal. Nesse sentido, as línguas indígenas passaram a ser perseguidas, não sendo reconhecidas como línguas, mas como gírias, língua não culta, uma forma de diminuir o prestígio que elas nunca tiveram.

Na contemporaneidade, as línguas que conseguiram chegar até aqui, chegaram em diferentes níveis de vitalidade. Algumas línguas, já moribundas, outras, fracas, com um número reduzido de falantes, mas todas estão cada vez mais expostas a uma competição desigual com as línguas hegemônicas. Nessa perspectiva, o povo Kokama entra, no século $\mathrm{XXI}$, rompendo as fronteiras geográficas, políticas, culturais e linguísticas entre o Brasil e o Peru em prol do fortalecimento da língua de seus ancestrais.

Nesse contexto, as novas tecnologias vieram contribuir para o ensino e a aprendizagem da língua Kokama por meio do multiletramento, aqui entendido como um conjunto de letramentos (desde os grafismos corporais até as novas tecnologias). Essa contribuição veio com a criação de aplicativos de saberes tradicionais, plantas medicinais, narrativas, matemática, histórias bíblicas, músicas e desenhos animados, bem como com a sistematização dos materiais didáticos. Isto é, os saberes peculiares de homens e mulheres indígenas em espaços virtuais.

Um dos resultados de pesquisa do período do meu doutorado foi a produção de materiais didáticos diagramados com programas que dão maior resolução aos desenhos, aos grafismos, às fotos e a toda identidade Kokama expressa nos livros. Todos os materiais didáticos pedagógicos Kokama e os aplicativos são bilíngues Kokama/Português ou Kukama/Espanhol.

A ampliação dos espaços para que a língua seja ocupada por meio da interação verbal e espiritual (dimensão espiritual da língua) possibilita a seus falantes a esperança de que a língua de seus ancestrais seja territorializada em todos os ambientes da aldeia em seu cotidiano. Para isso, é importante que todos os envolvidos (ou a sua maioria) estejam 
dispostos a dar sua parcela de contribuição em prol do projeto de vitalização da língua de seus ancestrais.

Nesse sentido, este artigo busca responder: como dialogar com a natureza da língua e os conceitos de vitalizar e revitalizar? Quais espaços são considerados importantes para vitalizar a língua? Qual é a perspectiva de vitalização da língua pelo povo e por quem os acompanha?

O artigo está dividido em seis seções. Esta introdução apresenta o tema geral do artigo e o panorama das seções seguintes. A segunda seção apresenta os pressupostos dos saberes Kokama, saberes estes repassados de geração a geração. A terceira seção introduz a metodologia da pesquisa, que está embasada no mapeamento situacional de cunho etnográfico - o mapeamento situacional é uma nova maneira de ver o trabalho de campo no território tradicionalmente ocupado, pois os próprios agentes sociais interagem, desde o início da pesquisa até o final, sem perder o vínculo com a instituição após a pesquisa. Esse mapeamento é de cunho etnográfico porque descreve o universo cultural do povo. A quarta seção apresenta as Terras Indígenas Kokama. A quinta seção aborda o movimento de vitalização da língua Kokama e traz a subseção "a vitalização da língua e os multiletramentos”. Finalmente, a última seção apresenta as considerações finais.

\section{PRESSUPOSTOS DOS SABERES KOKAMA}

O povo Kokama habita a Amazônia brasileira, peruana e colombiana. Desde o século XVI, há registros desse povo por naturalistas, viajantes, antropólogos, linguistas, entre outros. Os registros relatam esse povo como cordial e excelentes pescadores, agricultores e caçadores. Os Kokama foram um dos primeiros povos a serem contactados, visto que habitavam a beira dos rios (ALMEIDA; RUBIM, 2012).

Por serem excelentes pescadores, eles abasteciam o mercado regional com peixes salgados (como pirarucu, tambaqui, pirarara, piraíba, surubim e outros peixes lisos); jabutis, tartarugas; e peixes de um modo geral (RUBIM, 2016). A palavra Kokama ou Kukama é formada por dois termos: Ku, 'roça', e kama, que quer dizer "aquele que se alimenta da roça" - nossa tradução (RIVAS, 2003, p. 9).

Desde a década de 1980, o movimento de fortalecimento da língua Kokama no Brasil e no Peru passou a se preocupar com o fortalecimento da língua e da cultura Kokama. No decorrer desse processo, muitas lideranças, como anciãos e anciãs, professores, estudantes, aprendizes, ouvintes, lembradores, entre outros, nos deixaram, voltaram para o território espiritual de nossos ancestrais.

A nova geração, juntamente com os anciãos que ainda estão conosco, continua a caminhada de vitalização da língua. Eu sou falante da língua Kokama como L2, sou de Santo 
Antônio do Içá, Amazonas. Meus pais são oriundos do rio Içá, do Japacuá, hoje Terra Indígena Ticuna Eware I. Tenho lembranças de minha tia-avó Olária Pinto Pereira falando em Kokama com meu tio-avó Manduca Pinto Pereira, conhecido como "Quebra banco" (exímio produtor de instrumentos de pesca), e de seus sotaques quando falavam a língua portuguesa. Quando criança, associei esse som ao som do enxame de abelhas "zzzzzzzzz". Outras vezes, associava o som a uma espécie de "zom, zom, zom, zom". Assim eu ouvia.

Isso, mais tarde, ao estudar a língua, descobri que era, em termos técnicos, o [ÿ]', que representa um alofone do fonema /y/. Por exemplo, a palavra yawara, 'cachorro', yawati, 'jabuti', yawapana, 'ariranha', yawaraiyutara, 'onça', tayatsu, 'queixada', entre outras, são pronunciadas como uma espécie de [dza]. Nesse sentido, as pronúncias de [dzawara], [dzawati] e das demais palavras levavam a fala de meus tios-avós, ambos já falecidos, a terem um som similar ao da abelha. Atualmente, apenas os Kokama da fronteira entre o Brasil e Peru falam essa variante da língua Kokama, "em relação ao emprego /y/ e /ÿ/ no Peru os Kukama-Kukamiria incluíram na escrita oficial o /ÿ/” (RUBIM, 2016, p. 264).

Tenho lembranças do meu tio Pedro Pereira contando histórias em Kokama. Ele ficava alegre comigo e dizia: "esse conhecimento não pode morrer, é preciso ser repassado". Meu tio Pedro era rezador de nossa comunidade. Todo final de tarde, as mães levavam seus filhos para ele rezar. Tio Pedro faleceu em dezembro de 2019. Minha tia Marcina, sua esposa, ensinou-me a história da Mama Kupia 'Mãe do Kupim' e a ikara amana wari 'música da chuva'. Meu tio partiu com mais de 94 anos. Minha tia tem 95 anos e continua a ensinar a língua.

Lembro de meu pai falando com minha tia Marcina, conversando em Kokama, mas quando nós, crianças, aproximávamo-nos, eles paravam de conversar. Lembro do primeiro ritual que o meu pai fez conosco, o ritual do "rabo da cobra". Quem cresce na Amazônia conhece os perigos da selva, mas, para todos os povos indígenas, essa convivência é harmônica desde que os saberes tradicionais sejam utilizados e respeitados. Nesse sentido, relatarei o que vivenciei nesse ritual.

Somos doze irmãos. Meu pai era Kokama e minha mãe era Kaixana. Cada um de nós tem uma diferença de dois anos. No dia do ritual, meu pai nos acordou cedo, depois de uma madrugada de chuva. Chamou as quatro últimas filhas e nos colocou uma ao lado da outra. Em nossa frente, estava uma folha de pariri com algumas bolinhas de barro e o rabo da cobra jararaca. Antes, meu pai tinha acordado mais cedo e tinha ido atrás de uma cobra para fazer o ritual. Ele fez um pequeno buraco na terra, um buraco profundo e lá de dentro tirou uma argila pura sem barro e sem areia. Pegou essa argila e fez as bolinhas que estavam na folha do pariri. Ele assobiava um canto, um ikaru, enquanto cortava em partes 
finas o rabo da cobra (mais tarde descobri que esse ikaru era o "ikaru da cobra", uma espécie de canto que faz neutralizar o veneno da picada da cobra). Depois de cortado, ele enrolou o rabo no barro e deu para que nós o engolíssemos. Assim o fizemos. Depois disso, ele disse: "agora vocês não serão picados por cobra nenhuma". Isso aconteceu. Todos os seus doze filhos se criaram e vivem na Amazônia sem ser picados pelas cobras.

Eu e meus irmãos crescemos ouvindo histórias, músicas, praticando rituais e aprendendo os afazeres do cotidiano Kokama. Meus irmãos aprendiam com meu pai e com meus tios a tecer tarrafa, a fazer anzol, a preparar diferentes tipos de zagaias e a pescar peixes pequenos, médios e grandes. Eles aprendiam a caçar aves e animais; a fazer roça; a fazer canoa, remo, entre outros. As mulheres aprendiam com sua mãe a fazer moqueado; a salgar peixes; a salgar tartaruga, jabutis, mujica, peixe assado, peixe cozido; a tratar peixe pequeno, médio e grande, com e sem escama; a preparar as caças com pena e com pelo; a plantar roça; descascar as mandiocas e macaxeiras; a fazer farinha; tirar goma; a fazer tucupi; a fazer diferentes tipos de beiju, entre outros. Todos esses saberes são repassados por nossos guardiões dos saberes tradicionais Kokama. Muitos já partiram, mas ainda temos mais guardiões e futuros guardiões que lutam para fortalecer a língua e a cultura de nossos ancestrais.

\section{METODOLOGIA}

A entrada de campo foi fundamentada numa relação de proximidade social e na familiaridade que assegurou a efetivação de uma comunicação não violenta (Bourdieu, 1997). Nessa perspectiva, a relação se pautou numa linguagem dialógica como mediadora e expressão do povo envolvido na pesquisa. Assim, trata-se de uma pesquisa baseada no mapeamento situacional da Nova Cartografia Social da Amazônia (Almeida, 2014) de cunho etnográfico (Haguette, 1992), por descrever o universo cultural de um povo indígena em planos sociais diversos numa relação contínua. Essa abordagem do mapeamento situacional rompe com a cartografia tradicional, conceituada pelo dicionário, e com as cartas topográficas dos mapas para criar uma nova forma de pensar a relação de pesquisa com os agentes sociais. Essa forma é pautada em diferentes planos de organização social que envolvem múltiplos agentes, os quais contribuem com a descrição de narrativas, de histórias antigas e do próprio território (Almeida, 2014).

O processo de vitalização de uma língua é um desafio para os povos indígenas e para os parceiros envolvidos (como linguistas, pedagogos, professores, organizações governamentais e não governamentais). Nessa perspectiva, os povos que decidem dar uma nova dinâmica à língua, por meio da vitalização, na contemporaneidade, utilizam várias estratégias, como os materiais didáticos físicos e digitais (a exemplo, temos: aplicativos, 
WhatsApp, entre outros). Diante disso, como dialogar com a natureza da língua e os conceitos de vitalizar e revitalizar? Quais espaços são considerados importantes para vitalizar a língua? Qual é a perspectiva de vitalização da língua pelo povo e por quem os acompanha?

\section{TERRAS INDÍGENAS KOKAMA}

A relação dos indígenas com a terra é intrínseca, como visto no significado do nome Kokama: "aquele que se alimenta da roça", aquele que se alimenta da mãe terra. As lutas pelas demarcações das terras indígenas ocorrem desde a década de 1980. Naquele período, os indígenas de várias etnias se reuniam para discutir problemas relacionados à terra, à saúde e à educação. As lideranças, comunidades e parceiros (como o Conselho Indigenista Missionário, representantes de universidades, entre outros) saíam de seus lugares e de suas casas e comunidades para se reunir. Eles levavam galinha, peixe, farinha, banana e carne de caça para compartilhar nos dias dos encontros.

As discussões originaram demandas levadas ao Governo Federal. Assim, os indígenas conquistaram, pela primeira vez na história do Brasil, os direitos garantidos pela Constituição Federal de 1988 - o direito dos povos indígenas às suas terras de ocupação tradicional. Portanto, a terra indígena não é criada por ato constitutivo, mas, sim, reconhecida a partir de requisitos técnicos e legais, nos termos da Constituição Federal de 1988 (FUNAl, 20b).

Nessa perspectiva, apresentamos a seguir o mapa das terras indígenas Kokama e o quadro das terras indígenas demarcadas e em processo de demarcação.

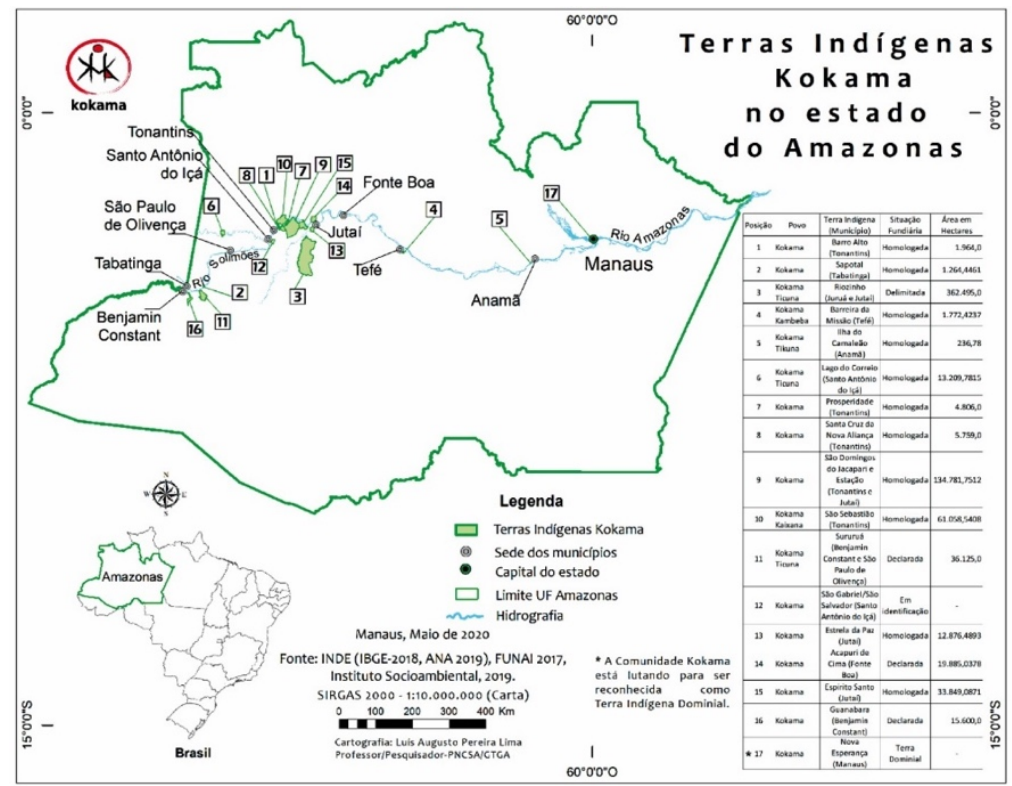

Figura 1. Terras indígenas Kokama.

Fonte: Formulação da própria autora. 


\begin{tabular}{|c|c|c|}
\hline POVO & TERRA INDÍGENA/MUNICÍPIO & SITUAÇÃO FUNDIÁRIA \\
\hline 1. KOKAMA & $\begin{array}{l}\text { TI Barro Alto/Tonantins } \\
1,9 \text { mil hectares }\end{array}$ & $\begin{array}{l}\text { Delimitada- 2006/Declarada - } \\
\text { 2007/Homologada-2011 }\end{array}$ \\
\hline 2. KOKAMA & $\begin{array}{l}\text { Sapotal/Tabatinga } \\
1,2 \text { mil hectares }\end{array}$ & $\begin{array}{l}\text { Delimitada-2005/Declarada- } \\
\text { 2006/Homologada-2011 }\end{array}$ \\
\hline 3. KOKAMA/TICUNA & $\begin{array}{l}\text { Riozinho/Juruá e Jutaí } \\
362.495 \text { hectares }\end{array}$ & $\begin{array}{l}\text { (Delimitada) Foi publicada, hoje (25), a Portaria } \\
n^{\circ} 485 \text {, de } 22 / 04 / 2016 \text {, assinada pelo Ministro } \\
\text { da Justiça. }\end{array}$ \\
\hline 4. KOKAMA/KAMBEBA & $\begin{array}{l}\text { Barreira da Missão²/Tefé/ } \\
1.772 \text { hectares }\end{array}$ & Homologada-1991 \\
\hline 5. KOKAMA e TIKUNA & $\begin{array}{l}\text { Ilha do Camaleão/Anamã/ } \\
184 \text { ha }\end{array}$ & Homologada-1995 REG CRI E SPU \\
\hline 6. KOKAMA e TICUNA & $\begin{array}{l}\text { Lago do Correio/Santo Antônio do } \\
\text { lçá / } 13.797 \text { há }\end{array}$ & $\begin{array}{l}\text { Delimitada-2006/Declarada- } \\
\text { 2007/Homologada-2009 REG CRI }\end{array}$ \\
\hline 7. KOKAMA & $\begin{array}{l}\text { Prosperidade/Tonantins } \\
5.491 \text { ha }\end{array}$ & $\begin{array}{l}\text { Delimitada-2006/Declarada - } \\
\text { 2007/Homologada-2009 REG CRI }\end{array}$ \\
\hline 8. KOKAMA & $\begin{array}{l}\text { Santa Cruz da Nova } \\
\text { Aliança/Tonantins } 5.762 \text { ha }\end{array}$ & $\begin{array}{l}\text { Delimitada-2006/Declarada - } \\
\text { 2007/Homologada-2012 }\end{array}$ \\
\hline 9. KOKAMA & $\begin{array}{l}\text { São Domingos do Jacapari e } \\
\text { Estação/Tonantins, Jutaí } \\
133.985 \text { ha }\end{array}$ & $\begin{array}{l}\text { Delimitada-2003/Declarada- } \\
\text { 2006/Homologada- 2009 REG CRI }\end{array}$ \\
\hline 10. KOKAMA e KAIXANA & $\begin{array}{l}\text { São Sebastião/Tonantins } \\
59.588 \text { ha }\end{array}$ & $\begin{array}{l}\text { Delimitada-2000/Declarada- } \\
\text { 2001/Homologada-2005 REG CRI }\end{array}$ \\
\hline 11. KOKAMA e TICUNA & $\begin{array}{l}\text { Sururuá/Benjamin Constant, São } \\
\text { Paulo de Olivença } \\
36.073 \text { ha }\end{array}$ & Delimitada-2008/Declarada-2010 \\
\hline 12. KOKAMA & $\begin{array}{l}\text { São Gabriel/São Salvador/Santo } \\
\text { Antônio do lçá }\end{array}$ & Em identificação (em estudo) \\
\hline 13. KOKAMA & $\begin{array}{l}\text { Estrela da Paz e São Domingos do } \\
\text { Jacapari/Estação/JUTAí }\end{array}$ & Homologada-1995 \\
\hline 14. KOKAMA & Acapuri de Cima/Fonte Boa & Delimitada-1999/Declarada-2000 \\
\hline 15. KOKAMA & Espírito Santo /Jutaí & $\begin{array}{l}\text { Delimitada-1999/Declarada- } \\
\text { 1999/Homologada-2005 }\end{array}$ \\
\hline 16. KOKAMA & $\begin{array}{l}\text { Guanabara/Benjamin/Constant } \\
15.600 \mathrm{ha}\end{array}$ & $\begin{array}{l}\text { Delimitada-2011/Declarada Portaria n }{ }^{\circ} 1.704 \text {, } \\
\text { de } 19 \text { de abril de } 2013 .\end{array}$ \\
\hline$* * 317$. KOKAMA & Nova Esperança $a^{4}$ Manaus & Terra Dominial $\left.\right|^{5}$ \\
\hline
\end{tabular}

No Brasil, há aproximadamente 700 T.ls (terras indígenas) em diferentes fases de demarcação (FUNAI, 2020) ${ }^{6}$. A sua maior parte está localizada na Amazônia Legal. As T.Is Kokama estão em diferentes fases de demarcação, algumas já conquistaram até a homologação, mas ainda há muita luta pela defesa do território, pela demarcação das T.Is Kokama, pois o bem-viver do povo está ligado à sua relação intrínseca com o território, que é a sua morada, o seu alimento e o seu espírito. O espírito é que alimenta a língua; dessa maneira, apresentamos o movimento de vitalização da língua Kokama.

Temos dezessete T.Is Kokama, sendo quinze Terras Tradicionalmente Ocupadas e duas Terras Dominiais. Trata-se de um território farto de plantas medicinais, espirituais

\footnotetext{
2 Terra Dominial Indígena.

3 Luta para ser reconhecida como Terra Dominial Indígena em Manaus.

4 Em processo de reconhecimento pela FUNAI.

5 "Terras Dominiais: São as terras de propriedade das comunidades indígenas, havidas, por qualquer das formas de aquisição do domínio, nos termos da legislação civil." (Fonte: http://www.funai.gov.br/index.php/indios-nobrasil/terras-indigenas).

6 http://www.funai.gov.br/index.php/indios-no-brasil/terras-indigenas. Acesso em: 05 mar. 2020
} 
e frutíferas; aves; peixes; animais; tartarugas; e jabutis. A dieta do nosso povo está na plantação de banana, milho, melancia, cará, macaxeira, abacaxi, entre outros. Atualmente, a nossa sobrevivência e a sobrevivência dos demais povos estão ameaçadas por garimpeiros, posseiros, madeireiros e pescadores de grande porte que avançam desenfreadamente nas T.Is.

O resultado desse avanço é visto com a chegada de doenças às nossas aldeias, pela contaminação da água e dos peixes; com o desmatamento; e agora com a chegada de novas doenças que deixam os povos indígenas vulneráveis. A mãe terra sofre e seus filhos sofrem também, pois há uma retroalimentação - como vimos anteriormente -, expressa no significado de ser Kokama, "aquele que se alimenta da terra". O alimento não é apenas físico, é espiritual. Se a mãe terra adoece, o físico e o espiritual também adoecem. Nessa perspectiva, apresentamos o movimento de vitalização da língua Kokama, a luta pela língua é tão importante quanto a luta pelo território.

\section{O MOVIMENTO DE VITALIZAÇÃO DA LÍNGUA KOKAMA}

No Brasil, Rodrigues (1984/85) classificou a língua Kokama como pertencente ao tronco linguístico Tupi, membro da família Tupi-guarani, subgrupo III, junto ao Tupinambá, devido à maioria de itens lexicais serem derivados desta língua, apesar das diferenças gramaticais entre elas. Para além das classificações linguísticas, os Kokama chegaram ao século XXI.

A luta pelo território e pela língua passou a ser a bandeira desse povo. A experiência que compartilharemos sobre o processo do movimento de vitalização da língua e sobre o uso das tecnologias possibilitará uma reflexão sobre o que povos como o Kokama fazem para ter sua língua fortalecida. Levou anos para percebermos que essa língua não estava sendo revitalizada, mas, sim, vitalizada. Foi gasta muita energia. Estávamos remando contra a correnteza de um rio forte.

Revitalizar é dar nova vida à língua. Línguas, que foram colocadas para ficar adormecidas em bibliotecas, museus e em outros espaços institucionais, por meio de cantos, poesias, histórias, vocabulários e narrativas, são acordadas no século XXI. Essas línguas são retomadas pelos povos, os verdadeiros guardiões desses saberes, que, conectados com os espíritos de seus ancestrais, dão um novo sentido à língua para atender a demanda da contemporaneidade.

Por estarem conectadas com o espírito dos ancestrais pela mãe terra, as línguas indígenas não morrem, mas adormecem, ficam silenciadas. Basta ter uma oportunidade e essas línguas voltam a ser faladas novamente. Isso é revitalização. Para que isso ocorra, primeiramente é preciso saber se o povo quer acordar sua língua; em seguida, fazer um esforço para buscar os lembradores da língua na aldeia; realizar pesquisa nas 
instituições (universidades, igrejas, museus, entre outros), verificar o que se tem da língua e solicitar a posse, como verdadeiros guardiões. O resultado desse esforço é o início do ritual para acordar línguas adormecidas. De posse desses pilares e mais o acompanhamento de linguistas, o povo começa a falar palavras, frases, a reconstruir o léxico e, muitas vezes, até a sintaxe da língua.

Revitalizar é diferente de vitalizar, pois as línguas nesse processo possuem falantes vivos. Elas não estão adormecidas, elas estão deixando de ocupar espaços. Um ritual que era feito antes, hoje não é feito mais. Os espaços dos anciãos ou anciãs de contar histórias foram substituídos por tecnologias eletrônicas e digitais.

Nesse sentido, também a língua precisa voltar a ocupar os espaços dessa aldeia, dessa comunidade. As metodologias de ensino de língua estão aí para contribuir com esse processo. Um grande exemplo é o povo Ticuna, que possui mais de vinte mil falantes, mas há comunidades no Alto Solimões, como a aldeia Santa Clara Tupi 1, no Rio Solimões, em São Paulo de Olivença-AM, que não estão falando a língua.

Na vitalização7, a língua precisa ocupar os espaços, fortalecer a dinâmica de sua existência. Mas, para isso, é preciso ganhar um status maior dentro da aldeia - assim como os guardiões da língua, os anciãos, os pajés, as lideranças tradicionais -, bem como no coração de cada membro do povo. A língua deve ocupar mais espaço nas escolas, nas igrejas, nos grupos de trabalhos, nos grupos de WhatsApp, nas assembleias e na própria comunidade. Deve ocupar também espaços na vida da aldeia, como em camisas de futebol para os jovens, na música, na dança, entre outros. Seria muito interessante que as narrativas indígenas estivessem presentes em desenhos animados, que a produção de material didático fosse realmente uma política linguística atendida pelo Estado e que não fosse feita de qualquer jeito.

No caso da atualização, ela está relacionada à entrada de novos léxicos na língua nativa, principalmente o léxico das novas tecnologias. Os Kokama fazem a tradução por meio do uso. Por exemplo, a tradução de 'microfone' é maripu kumitsa eretsepan: 'coisa que fala forte'; a de 'câmera fotográfica' é maripu tsanata, em que mari-pu é 'coisa' e tsanata é 'imagem-tradução'. Mas os Kokama também fazem a tradução pelo uso e pela forma literal da palavra, por exemplo, 'microfone' é churananin pun=ipun, em que churananin-ipun é ‘som' e churananiné 'pequeno' (RUBIM, 2016). Outro exemplo é o de 'celular', kumitsa-tata, em que se tem 'falar-CAU reduplicado', sendo o significado literal: 'aquilo que faz falar'. Nesse contexto, o léxico atualizado precisa ser constantemente utilizado em todos os ambientes para poder conquistar espaço; caso contrário, não será utilizado pelo povo.

7 A esse respeito, ver RUBIM e FAULSTICH (2020)

$8 \mathrm{CAU}=$ Causativo reduplicado, 'tata'. 
A língua Kokama está sendo ensinada como segunda língua, mas não como língua estrangeira, como algo estranho à cultura, à vida do povo. É uma segunda língua porque é aprendida depois da L1. Nesse processo, a língua é mais que uma gramática a ser aprendida. Ela é espírito. Ela conecta a vida de um povo com a sua ancestralidade, pois, no dia a dia dos povos indígenas, são vivenciadas as práticas culturais do cozinhar, do pescar, do fazer teçumes, do artesanato, da cerâmica e de tantas outras formas de viver a cultura. Quando se aprende a língua indígena como segunda língua, o agente social se reconecta com a sua ancestralidade.

Nesse sentido, a metodologia de ensino de língua precisa ser repensada. Nesse contexto, os Kokama estão dialogando com várias teorias de ensino de língua (como a abordagem comunicativa e interacionista), além de colocar em prática sua própria forma de ensino de língua, baseado na oralidade, na contextualização, no visual, na audição e na escrita.

O movimento da vitalização da língua Kokama segue o curso do rio, não pode parar. Os primeiros encontros para falar sobre a língua na capital do estado do Amazonas começaram em 2005, com Sebastião Castilho Gomes, kuraka Kokama desse município, convocando os Kokama de Manaus para fortalecer a língua e a cultura Kokama. A convocação foi atendida e, desse encontro, saiu um documento encaminhado ao Conselho Indigenista Missionário - CIMI. O resultado foi a primeira oficina realizada pelo padre e linguista Ronald MacDonell com os indígenas Kokama de Manaus.

Desde então, todos os anos, ele chegava ao Brasileirinho para realizar a oficina, e conseguiu preparar os professores para continuar o trabalho. A aldeia Nova Esperança Kokama do ramal do Brasileirinho no Km-08, passou a ser o ponto de todos os Kokama de Manaus e do entorno para encontros e discussões sobre a língua de seus ancestrais. A comunidade, juntamente com seus professores, com o CIMl e com a secretaria Municipal de Educação e a Universidade de Brasília, passaram a produzir os materiais didáticos.

Assim, foi se desenhando a política de vitalização da língua. Ainda em 2005, foi realizada uma assembleia para escolha do professor para ensinar língua e cultura na comunidade. O professor e sua irmã, professora da SEMED/Manaus, passaram a organizar a produção dos materiais. A mobilização na comunidade foi grande. Foram realizadas dramatizações das histórias Kokama, festas com as comidas e bebidas típicas, produção de roupas típicas com os grafismos do povo, entre outros.

No decorrer desses anos, cada ano foi dedicado a uma luta em prol da língua. Os caminhos da aldeia foram nomeados com nomes na língua Kokama. Na entrada da comunidade, foi colocado um cartaz com os dizeres "bem-vindo" na língua Kokama, em português, em espanhol e em inglês. A horta da comunidade recebeu um nome, o barracão, a casa de farinha, e demais espaços coletivos receberam um nome na língua indígena. 
Dessa maneira, foram produzidos materiais didáticos bilíngues. A coletânea Yawati Tinin, 8 (oito) histórias em quadrinhos, 2 (dois) paradidáticos, além das produções realizadas pelo próprio professor indígena da comunidade. Com o avanço da formação dos professores Kokama, agora passando a ter uma linguista do próprio povo, formada pela Universidade de Brasília, a produção de material didático aumentou, assim como o atendimento foi estendido às demais comunidades Kokama da Amazônia Brasileira, com parceria dos Kokama da Amazônia peruana.

Em Manaus, foram criados os Centros de Educação Escolar Indígena, os Centros de Ciências e Saberes Tradicionais Kokama, conhecidos como museu vivo. Esses espaços ensinam a língua e a cultura Kokama, em parceria com a SEMED/Manaus, Projeto Nova Cartografia Social da Amazônia e as comunidades. Nas escolas estaduais, no interior do Amazonas, as escolas indígenas passaram a ter a disciplina de língua indígena na escola.

A demanda por formação de professores Kokama na sua língua aumentou. Apresentamos um projeto para o Instituto Federal do Amazonas em Tabatinga, mas este foi engavetado com a política do atual governo. Nesse contexto, o povo Kokama assumiu a responsabilidade de fortalecer a língua de seus ancestrais. Criamos a "Oficina de Ensino e Aprendizagem da Língua Kokama”, uma oficina itinerante que está na sua XIII edição. Todo ano ela está em um município do estado do Amazonas. Os professores Kokama de outros municípios e até do Peru se organizam para estar presentes.

Na oficina, trabalhamos a gramática, a sintaxe, as dramatizações das narrativas do povo, as danças, a troca de materiais didáticos físicos e digitais, os aplicativos e atividades culturais com as crianças, além de realizar a coleta de dados da pesquisa para a criação do dicionário infanto-juvenil bilíngue português/kokama. A duração da oficina varia entre três e quatro dias. Além disso, temos um espaço para discutirmos temas como educação escolar indígena, saúde e território.

Além da oficina itinerante, temos outras oficinas que ocorrem em Tabatinga, Benjamin Constant, São Paulo de Olivença, Santo Antonio do Içá, Amaturá, Tonantins, Jutaí, Fonte Boa, Coari, Tefé, Alvarães, Manaus, Rio Preto da Eva, entre outros. Todas as oficinas somam com o fortalecimento da língua e com a educação escolar indígena do povo.

Hoje, os Kokama têm orgulho de ser Kokama, de ter a língua de seus ancestrais conquistando cada dia mais espaço na aldeia. Recentemente, conseguimos uma parceria entre a Universidade de Brasília, por meio da linguista do povo Kokama, e a Universidade do Estado do Amazonas para termos um curso da língua Kokama via WhatsApp e Telegram. Esse curso tem a duração de dois anos e é dividido em módulos, com lições interativas oferecidas para os Kokama do estado do Amazonas. A equipe do curso, coordenada pela linguista do povo, conta com os estudantes de iniciação científica do curso de Licenciatura em Português do Brasil como Segunda Língua - PBSL da Universidade de Brasília. Como se 
vê, a vitalização está ligada à prática social da língua, seus usos na dinâmica da vida do homem e da mulher Kokama, com seus múltiplos significados, seus multiletramentos.
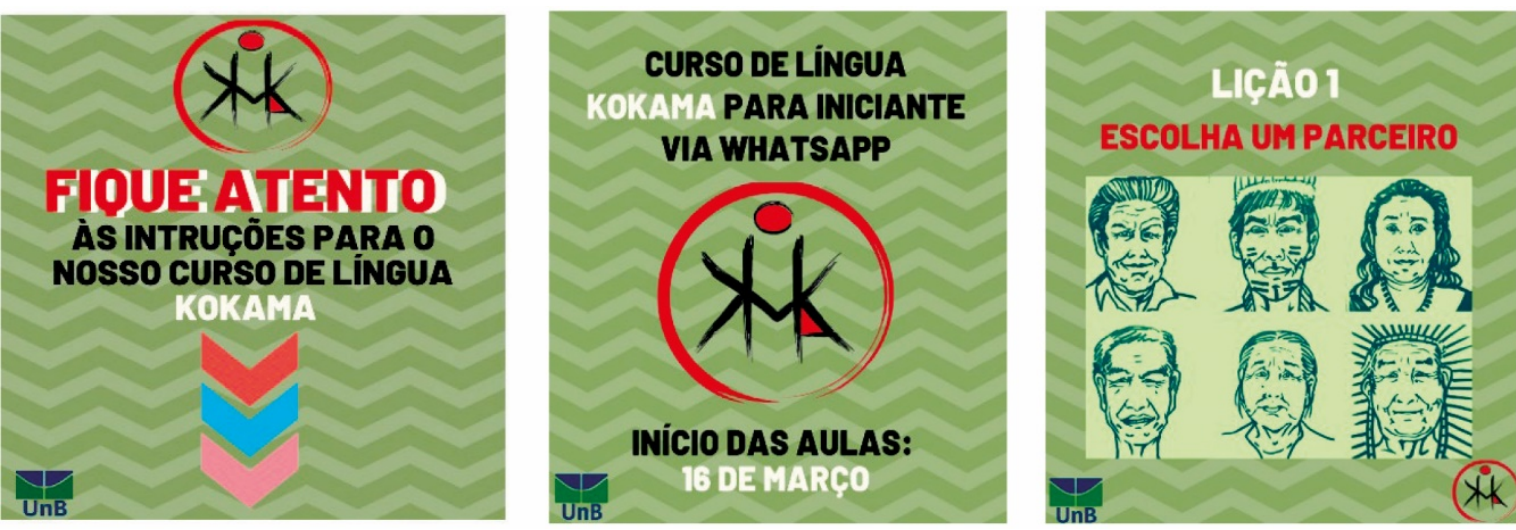

Figura 2. Material do curso preparado pelos estudantes do PBSL/UnB, 2020. Fonte: Acervo da própria autora.

\subsection{A VITALIZAÇÃO DA LÍNGUA E OS MULTILETRAMENTOS}

Vitalizar uma língua é dar força a ela, é fazê-la ocupar espaços nas músicas, nos rituais, nas rezas, nas orações, nas danças, nas brincadeiras, nas piadas, nas contações de histórias, nos discursos do cotidiano, nas dramatizações, nos grafismos utilizados de diferentes formas, com diferentes significados e no cotidiano da comunidade. A língua precisa estar presente na preparação das comidas, na produção dos instrumentos de caça e de pesca, na elaboração do planejamento de aula.

Nesse sentido, a figura a seguir apresenta o cotidiano cultural que vitaliza a língua. As pinturas nas roupas Kokama, feitas pelos jovens das comunidades, para as festas. A brincadeira das crianças do cipó ambé. A professora Jardeline Santos, do Centro Antônio Samias, que realiza a atividade com seus aprendizes. Cada expressão cultural é recheada de simbolismos que os mais jovens aprendem cantando, desenhando, brincando, o jeito de ser e viver do seu povo. Nessa perspectiva, o primeiro objetivo da vitalização da língua está sendo alcançado, pois a identidade Kokama de crianças, jovens e adultos cada vez mais se fortalece nesse processo. 


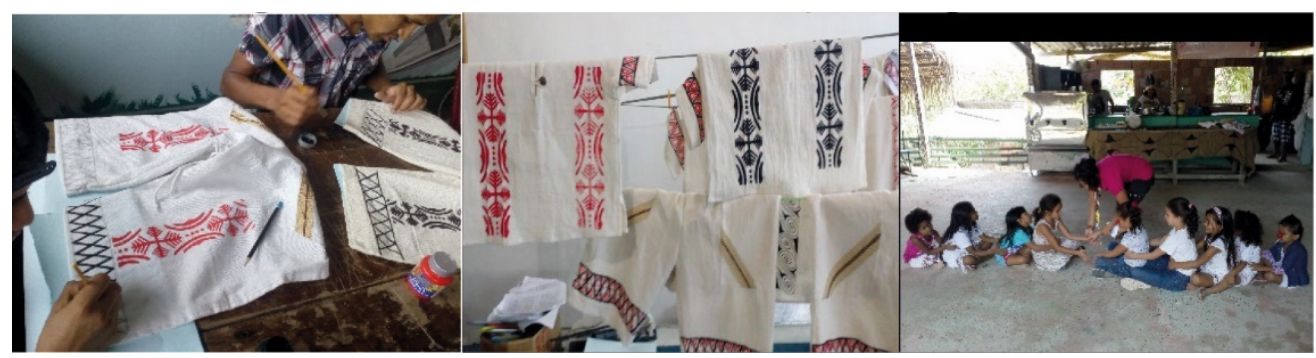

Figura 3. Cotidiano cultural da vitalização da língua kokama.

Fonte: Arquivo pessoal. Centros de Ciências e Saberes Tradicionais Kokama Lua Verde e Antonio Samias, 2018.

As diferentes formas que os Kokama estão buscando para vitalizar sua língua estão relacionadas à abordagem de ensino e aprendizagem criada pelo próprio povo (por meio de desenho, oralidade, escrita, contexto e audição), a qual dialoga com os multiletramentos de Rojo e Moura (2019). As linguagens mudaram no século XXI. As formas de produzir material didático e de conceber os saberes estão passando por transformações. Um material didático produzido atualmente exige do aprendiz vários conhecimentos ou saberes, pois apresentam músicas, mapas, diferentes gêneros textuais interativos, imagens estáticas e conteúdos interativos que exigem do seu público mais de um letramento.

Ao observar um material didático indígena, o aprendiz ou o leitor precisa saber os significados das cores, das letras, dos grafismos e das histórias. Saberes estes que possibilitam melhor compreensão do processo de ensino e aprendizagem da língua. Cada morfema, cada partícula, tem um significado, tem um saber que representa a forma de conceber o mundo de cada povo.

Atualmente, os materiais didáticos estão passando por mudanças. Eles são criados em computador com diferentes programas. São materiais didáticos multimodais. O que hoje é criado no computador, os povos indígenas já faziam e fazem com elementos da natureza. A multimodalidade ou o multiletramento estão presentes em todas as imagens que são colocadas no material didático - nos grafismos, nos remédios, nas plantas medicinais. Vejamos nas figuras seguintes o exemplo do material didático Kokama para surdo-cego, uma história antiga do povo Kokama (todos os materiais foram doados pelos Kokama do Amazonas).

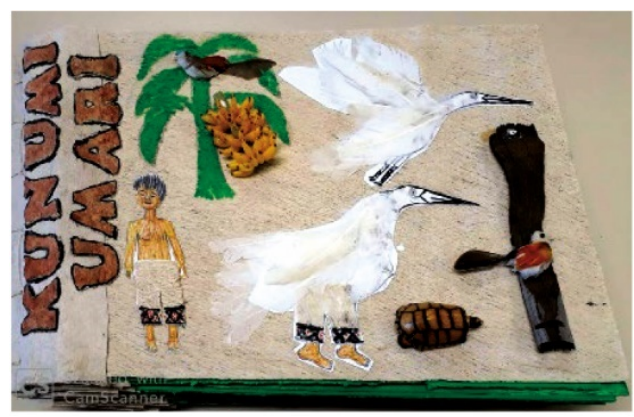

Figura 4. Material didático Kokama para surdo-cego. Fonte: Doação dos Kokama do Amazonas. 
Foi necessário criar uma caixa para transportar o livro, por este possuir a matériaprima in natura para que os surdos e cegos pudessem aproveitar o máximo de informação do livro. A capa do livro é feita de tururi (celulose extraída de árvores, como castanhas e da árvore tururi). Ela foi desenhada e pintada com tintas naturais de goiaba-de-anta e tinta de folha de capim. A madeira é um cavaco da árvore preciosa, uma árvore cheirosa que é utilizada para fazer chá para combater dor de barriga e que também serve como madeira para fazer casa. Pelo cheiro, o estudante conhece essa árvore. Pelo toque, descobre a pena da garça, o jabuti, a banana e o próprio papel de tururi.

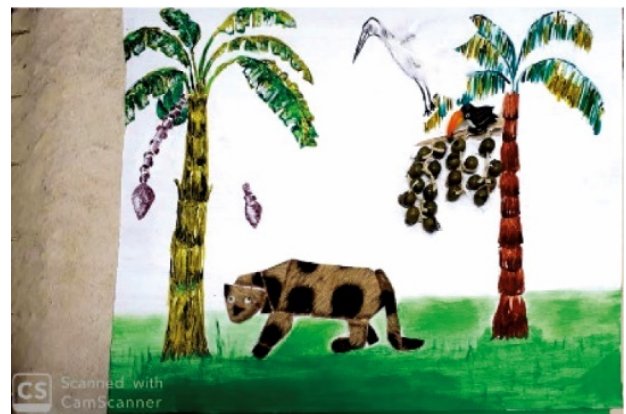

Figura 5. Amostra de uma página do livro.

Fonte: Doação dos Kokama do Amazonas.

Nessa página, o estudante pode tocar e sentir a pele da onça, o caroço e o cheiro do açaí, experiência concreta da vida de uma aldeia. Trata-se, portanto, de um material tridimensional, multimodal, que exige do leitor conhecimentos culturais para dialogar com o material. Aqui, exemplificamos duas páginas do livro, que está na Universidade de Brasília, todo feito no tururi.

E o que dizer das histórias Kokama que são contadas (oralidade), posteriormente escritas em livros, e transformadas em jogos para que os participantes possam vivenciar os personagens das histórias e, em seguida, brincar com eles. Isso exige multiletramentos. Vejamos nas figuras a seguir, o exemplo da capa do livro em que está registrada a história do jovem garça e, na sequência, o jogo do jovem garça:

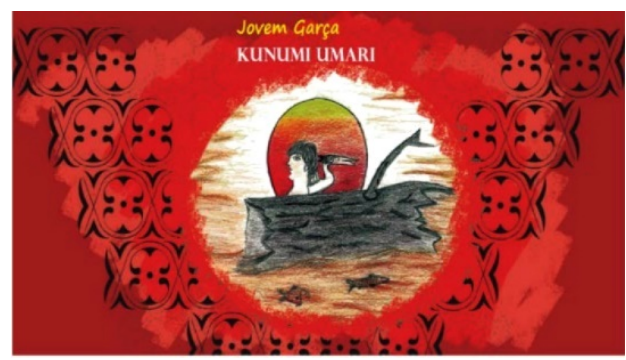

Figura 6. Capa do livro Jovem garça.

Fonte: Rubim (2016, p. 227) 

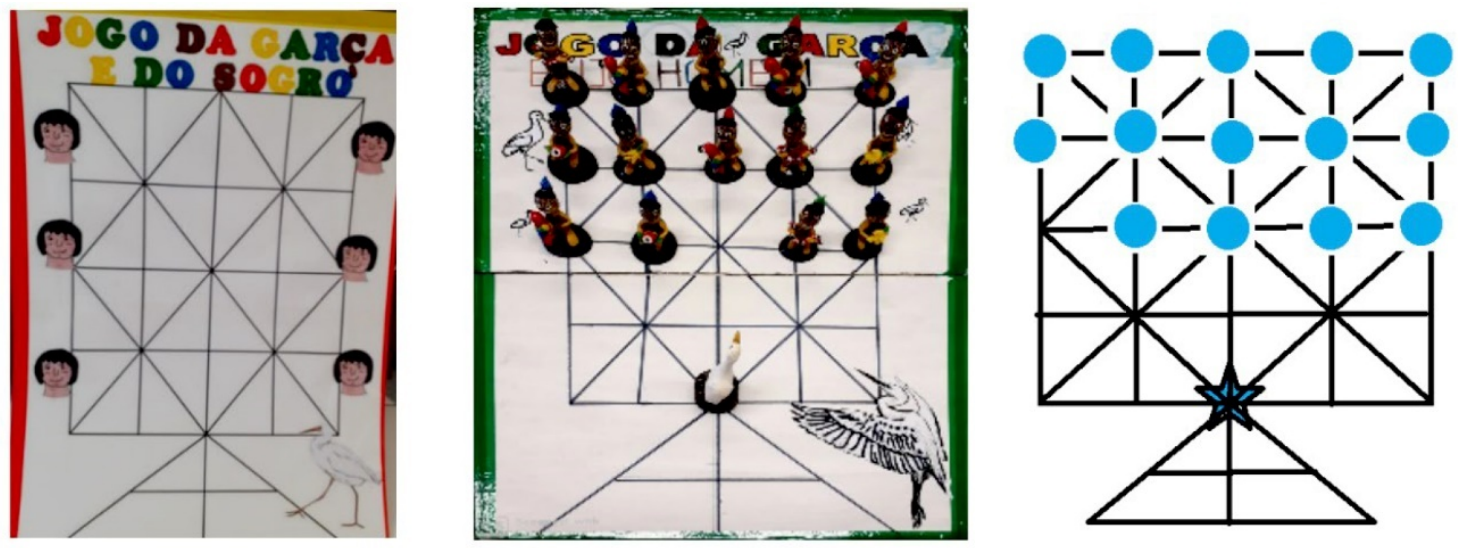

Figura 7. Jogos criados a partir das histórias antigas Kokama. Fonte: Fotos do acervo pessoal de Rubim. ${ }^{9}$

O objetivo do jogo é desenvolver o raciocínio lógico, a partir das histórias antigas indígenas, e vivenciar o personagem da história. Na produção desse jogo, foram utilizadas sementes de tucumã, paxiubinha, cortiça, tinta natural e artificial, além de papel paraná, pincel e fita colorida. Os aprendizes aprendem a língua na interação com outros participantes do jogo.

Desdobramento da história antiga foi o jogo pedagógico da "Garça com seu sogro", mencionada anteriormente, e a brincadeira da "Corrida da Garça". Quem participar dessa corrida deverá formar uma dupla (ou um trio). O participante que ficar na frente deverá colocar uma das pernas para trás, para o segundo participante segurá-la. Na sequência, o segundo participante também deverá colocar uma das pernas para trás e se apoiar com um dos braços no participante da frente. Assim, a corrida em dupla será realizada em duas voltas. O que liderar a corrida na primeira volta vai para trás, para que o participante de trás dele possa assumir. Essa brincadeira também pode ser adaptada para os cegos.

Essas histórias também podem ser encontradas em aplicativos Kokama, como os aplicativos Wawa Kukama, Mitologia Kokama, 5fish cocama, Kokama Tradutor, Kukamate e Artezania Kukama. Estes são aplicativos interativos que estão contribuindo com a vitalização da língua Kokama. Trata-se de uma relação da língua com as novas tecnologias, que contribuem no processo de ensino e aprendizagem da língua.

As histórias trazem um texto rico em conhecimento linguístico e cultural com multiletramentos. As tecnologias dos povos tradicionais, assim como as tecnologias digitais, precisam ter a mesma valorização. Produzir uma canoa, uma armadilha de caça

9 Materiais utilizados nos jogos pedagógicos de ensino e aprendizagem da língua Kokama no centro de Ciências e Tradicionais Lua Verde. Esses jogos também foram utilizados nas ações desenvolvidas na Semana Universitária da Universidade de Brasília, 2019 
ou um remo envolve saberes e conhecimentos que precisam estar presentes e dialogando com outros saberes na escola. Para Rojo e Moura (2019), multiletramento é prática, é usar as coisas para compreender criticamente a realidade. O multiletramento é diferente de letramento, que está ligado a leitura e escrita de um texto. O multiletramento aponta para a diversidade de linguagens.

\section{CONSIDERAÇÕES FINAIS}

Este artigo, através da experiência do povo Kokama, buscou responder as seguintes perguntas: como dialogar com a natureza da língua e os conceitos de vitalizar e revitalizar?; quais espaços são considerados importantes para vitalizar a língua?; e qual é a perspectiva de vitalização da língua pelo povo e por quem o acompanha?

Quando os conceitos de vitalizar, revitalizar e atualizar ficam claros, é possível ver os objetivos e as metas alcançadas pela política linguística do povo. Os processos de ensino e aprendizagem de uma língua indígena são peculiares a cada povo. Vitalizar, revitalizar e atualizar as línguas dos povos indígenas são processos necessários, seja como primeira ou segunda língua. O caminho que percorremos não deixa dúvidas de que precisamos continuar, precisamos desbravar, pensar de que forma nós, povos indígenas, podemos envolver mais as nossas crianças, os nossos jovens, a comunidade e, principalmente, valorizar mais os nossos anciãos, guardiões dos saberes ancestrais.

Precisamos formar mais linguistas indígenas, professores comprometidos com as línguas indígenas. Precisamos formar mais jovens para apoiar a política linguística de cada povo, também na área das novas tecnologias. Precisamos unir forças com as instituições parceiras para juntos construirmos uma política linguística que contemple financiamento para línguas em diferentes estágios de vitalidade. E, assim, pressionarmos o Estado a cumprir as leis que promovem a educação escolar indígena, a defesa de territórios, o bemviver dos povos indígenas e a valorização da língua de seus ancestrais, além de financiar a produção e a publicação de livros didáticos.

Precisamos cooficializar mais línguas indígenas e dar a elas um novo status no município em que estão localizadas. Precisamos lutar para as línguas indígenas ocuparem cada vez mais espaços físicos e virtuais. Neste aspecto, não podemos esperar apenas o financiamento do governo. Vamos fazer a nossa parte, compartilhando e passando saberes de geração a geração. Não permitamos que nossas línguas venham a adormecer novamente, mas nos unamos para fortalecê-las.

Por fim, acredito que os povos indígenas que lutam para manter viva sua língua sabem o tesouro espiritual que ela representa. Isso podemos ver expresso na língua e na cultura. 


\section{REFERÊNCIAS}

ALMEIDA, Alfredo Wagner Berno de. Conferência Inaugural: apontamento para uma "Nova descrição": uma abordagem crítica sobre a politização da consciência das fronteiras da Amazônia ao Prata. In: ALMEIDA, Alfredo Wagner Berno de; PICOTTI, Dina V. (Orgs.). De la pan-amazonia al rio de la plata: jornadas conocimientos tradicionales. Manaus: UEA. Edições; Los Polvorines, Buenos Aires: UNGS, 2014.

ALMEIDA, Alfredo Wagner Berno de; RUBIM, Altaci Corrêa. Kokama: a reconquista da língua e as novas fronteiras políticas. Revista Brasileira de Linguística Antropológica, v. 4, n. 1, p. 67-80, jul. 2012.

BOURDIEU, Pierre. A Miséria do mundo. Petrópolis, RJ: Vozes, 1997.

FUNAI. Tabela terras indigenas (atualizada em 08/02/2017). Disponível em: http://www.consultaesic.cgu.gov.br/busca/dados/Lists/Pedido/Attachments/533777/RESPOSTA_RECURSO_1 _08850000290201749\%201\%20Inst.TABELA_TERRAS_INDIGENAS.pdf. Acesso em: 14 fev. 2020.

FUNAI. Terras indígenas: o que é?(20--b). Disponível em: http://www.funai.gov.br/index.php/nossasacoes/demarcacao-de-terras-indigenas. Acesso em: 14 abr. 2020.

GÂNDAVO, Pero de Magalhães. Tratado da terra do Brasil: História da Província Santa Cruz, a que vulgarmente chamamos Brasil. Edições Senado Federal, vol.100. Brasília: Senado Federal, Conselho Editorial, 2008. Disponível em:

https://www2.senado.leg.br/bdsf/bitstream/handle/id/188899/Tratado\%20da\%20terra\%20do\%20Brasil.pdf?s equenc. Acesso em: 14 fev. 2020.

HAGUETTE, Teresa Maria Frota. Metodologias qualitativas na Sociologia. Petrópolis: Vozes, 1992.

KALANTZIS Mary; COPE Bill. Multiliteracies. 2019. Disponível em: https://newlearningonline.com/multiliteracies. Acesso em: 31 jul. 2019.

RIVAS RUIZ, Roxani. Uwarita: Los Kukama-Kukamiria y su bosque. Série: Um instrumento, Um mundo. Trampas de caza de los pueblos indígenas amazônicos. FORMABIAP Instituto Superior Pedagogico Público Loreto/Associación Interétnica de la Selva Peruana (AIDESEP): Iquitos, 2003.

RODRIGUES, Aryon Dall'lgna. Relações internas na família linguística Tupi-Guarani. Revista de Antropologia, v. $27 / 28$, p. $33-53,1984-1985$.

ROJO, Rojane Helena; MOURA, Eduardo. Letramentos, mídias, linguagens. São Paulo: Parábola Editorial, 2019.

RUBIM, Altaci Corrêa. O reordenamento político e cultural do povo Kokama: a reconquista da língua e do território além das fronteiras entre o Brasil e Peru. 323f. Tese (Doutorado em Linguística) - Departamento de Linguística, Português e Línguas Clássicas, Universidade de Brasília, Brasília, 2016.

RUBIM, Altaci C.; FAULSTICH, Enilde. Política de vitalização de uma Língua Indígena para além das fronteiras entre Brasil e Peru. South American Journal of Basic Education, Technical and Technological, v. 7 n. Sup. 2 (2020): Dossiê Léxico, Terminologia e Políticas Linguísticas. Disponível em:

https://periodicos.ufac.br/index.php/SAJEBTT/issue/view/175. Acesso em: 20 mai. 2020. 